\title{
Blade Runner 2049 and the Quest for Industry 4.0
}

\author{
VANIA V. ESTRELA* and EDWIGES G. H. GRATA \\ Universidade Federal Fluminense (UFF) Rio de Janeiro, Brazil.
}<smiles>O</smiles>

\section{Article History}

Publishied on: 30 October 2017

\begin{abstract}
Yes, I am a huge Sci-Fi and noir fan, but I also know where my feet are. As R\&D people, we must discuss emerging technology, standards and ethics fueled by this not so futuristic film.

Industry 4.0 (formerly known as Industrie 4.0) is a subset of the Internet of Things with some industrial things added devised by the German industry sector ${ }^{1}$. Its recommendations describe the combined interaction between Cyber-Physical Systems (CPSs), smart factory and the cloud. The product is designed with the way it will be produced, the form it will relate to its associated information, its place in the smart factory as well as collaboration with similar industrial units in mind.
\end{abstract}

Nevertheless, it seems to affect more than the industrial segment because, in one way or the other, everybody will be impacted by it. From the hermit who just want to forget about any type of problem (but has bills to pay and needs to buy food) to the illiterate small farmer who does not have electricity at home but sells some of his/her goods, nobody is out of its reach. Consequently, Industry 4.0 should be implemented according to an interdisciplinary fashion and in close cooperation with other key knowledge areas and sectors.

Robots, autonomous vehicles, the Internet of Things (IOT), high-speed transportation (Hyperloop One)2, personal drones and alternative energy sources are Scientific Reality (Sci-Real) now. The first Blade Runner movie talked about technology and corporations, and now most of that is too Sci-Real for comfort.

Recently, during a meeting, I have heard someone asking me why I used the "buzzword" Cyber-Physical System. Well, because we live in a Cyber-physical world! It is time to discuss critical issues such as:

- The relationship between individuals, corporations, and machines.

- The way soft robotics can build more human-like robots and why we need them.

- How humans and machines can soundly collaborate.

CONTACT Vania V. Estrela vania.estrela.phd@ieee.org $\mathbf{9}$ Universidade Federal Fluminense (UFF) Rio de Janeiro, Brazil. (c) 2017 The Author(s). Published by Techno Research Publishers

This is an $\bigcirc$ Open Access article licensed under a Creative Commons Attribution-NonCommercial-ShareAlike 4.0 International License (https://creativecommons.org/licenses/by-nc-sa/4.0/), which permits unrestricted NonCommercial use, distribution, and reproduction in any medium, provided the original work is properly cited.

To link to this article: http://dx.doi.org/10.13005/ojcst/10.04.01 
- $\quad$ The automation impact on jobs and healthcare.

- When technology becomes disruptive, what it demands and what to think and reorganize when itcomes to all facets of life, work, and society.

- What are the consequences of having blind faith in an artificial world?

- What else is in store for us?

We have reached a point where people use the terms loT $^{3}$ and Industry 4.0 as synonyms, although it is understandable since both can affect the whole supply chain. Initially, Industry 4.0 can optimize the supply chain management. Moreover, it can use sources effectively. Transparency can improve the whole supply chain and make real-time management feasible with extraordinary agility and complete integration. All that accomplished by using the concepts of CPSs and Smart Objects with or without cloud computing and IoT.

As multifaceted CPSs mix various devices able of sensing, identifying, processing, communicating, handling Big Data, and networking. Specifically, sensors and actuators are getting more and more powerful, cheaper and smaller, which allows their ubiquitous use.

As the concept of CPS is in the initial stage of development, it is essential to delineate its structures, methodologies, and implementations as clear guidelines for the industry and other domains. To meet these demands, a unified system framework will facilitate design and deployment of general applications. Furthermore, establishing the correspondence between algorithms and technologies at each system layer with the unified structure collaboration and realization of the desired functionalities of the overall system will help to enhance efficiency, reliability and product quality of both designs and products.

Progress is not a demon. What harms humanity is how we handle technology and our need to control each other's lives. Paradoxically, we are less sensitive to other fellow humans and obsessed with imposing our beliefs and lifestyles on others. We can embrace the pervasive and global nature of today's life and make it work for us, while not neglecting personal and local needs. Developing countries can benefit from the concepts as mentioned earlier to solve problems related to sanitation, power distribution/generation, and education without relying on gigantic projects. With local energy needs and other demands identified, then the need for massive government intervention and investments may decrease, which lead to all types of networking and remote interaction.

\section{Refrences}

1 Kagermann, H., Wahlster, W., and Helbig, J., 2013, Securing the future of German manufacturing industry Recommendations for implementing the strategic initiative INDUSTRIE 4.0 Final report of the Industrie 4.0 Working Group, http://www.acatech.de/fileadmin/user_upload/Baumstruktur_nach_ Website/Acatech/root/de/Material_fuer_Sonderseiten/Industrie_4.0/Final_report_Industrie_4.0_ accessible.pdf

2 Hawkins, Andrew (April 4, 2017). The hyperloop is ready for its big 'Kitty Hawk' moment — and may be coming to a US city near you. The Verge. US. Retrieved October 20, 2017.

3 Xu, L-D., He, W., and Li, S., 2014. Internet of Things in industries: a survey, IEEE Transactions on Industrial Informatics, Vol. 10, No. 4 , 2233-2243. DOI: 10.1109/TII.2014.2300753 